ARTICLE

\title{
Extracellular MRP8/14 is a regulator of $\beta 2$ integrin-dependent neutrophil slow rolling and adhesion
}

Monika Pruenster ${ }^{1}$, Angela R. M. Kurz¹, Kyoung-Jin Chung ${ }^{2}$, Xiao Cao-Ehlker ${ }^{1}$, Stephanie Bieber ${ }^{1}$, Claudia F. Nussbaum¹, Susanne Bierschenk ${ }^{1}$, Tanja K. Eggersmann ${ }^{1}$, Ina Rohwedder ${ }^{1}$, Kristina Heinig$^{1}$, Roland Immler ${ }^{1}$, Markus Moser ${ }^{3}$, Uwe Koedel ${ }^{4}$, Sandra Gran ${ }^{5}$, Rodger P. McEver ${ }^{6}$, Dietmar Vestweber ${ }^{7}$, Admar Verschoor ${ }^{8}$, Tomas Leanderson ${ }^{9}$, Triantafyllos Chavakis ${ }^{2}$, Johannes Roth ${ }^{5}$, Thomas Vogl ${ }^{5, *}$ \& Markus Sperandio ${ }^{1, \star}$

Myeloid-related proteins (MRPs) 8 and 14 are cytosolic proteins secreted from myeloid cells as proinflammatory mediators. Currently, the functional role of circulating extracellular MRP8/14 is unclear. Our present study identifies extracellular MRP8/14 as an autocrine player in the leukocyte adhesion cascade. We show that E-selectin-PSGL-1 interaction during neutrophil rolling triggers Mrp8/14 secretion. Released MRP8/14 in turn activates a TLR4mediated, Rap1-GTPase-dependent pathway of rapid $\beta 2$ integrin activation in neutrophils. This extracellular activation loop reduces leukocyte rolling velocity and stimulates adhesion. Thus, we identify Mrp8/14 and TLR4 as important modulators of the leukocyte recruitment cascade during inflammation in vivo.

\footnotetext{
${ }^{1}$ Institute of Cardiovascular Physiology and Pathophysiology, Walter-Brendel-Centre of Experimental Medicine, Ludwig-Maximilians Universität, Munich, Germany. ${ }^{2}$ Department of Clinical Pathobiochemistry, Institute for Clinical Chemistry and Laboratory Medicine, Technische Universität Dresden, Dresden, Germany. ${ }^{3}$ Department of Molecular Medicine, Max Planck Institute for Biochemistry, Martinsried, Germany. ${ }^{4}$ Department of Neuroinflammation, LudwigMaximilians Universität, Munich, Germany. ${ }^{5}$ Institute of Immunology, University of Muenster, Muenster, Germany. ${ }^{6}$ Cardiovascular Biology Research Program, Oklahoma Medical Research Foundation, Oklahoma City, OK, USA. ${ }^{7}$ Max Planck Institute for Biomolecular Medicine, Münster, Germany. ${ }^{8}$ Institute for Medical Microbiology, Immunology and Hygiene, Technische Universität, Munich, Germany. ${ }^{9}$ Immunology Group, University of Lund, Lund, Sweden.

* These authors contributed equally to this work. Correspondence and requests for materials should be addressed to M.S. (email: markus.sperandio@lmu.de).
} 
$\mathrm{M}$ yeloid-related protein 8 (MRP8, also known as S100A8 or calgranulin A) and myeloid-related protein 14 (MRP14, S100A9, calgranulin B) are two members of the S100 family, characterized by two calcium-binding EF-hand motifs, which are connected by a central hinge region ${ }^{1,2}$. They form a heterocomplex (MRP8/14, also known as calprotectin), which is considered to be the physiologically relevant form ${ }^{3}$, and are found in the cytosol of neutrophils representing $40 \%$ of the cytosolic protein content in neutrophils ${ }^{4}$. The Mrp8/14 complex is released from myeloid cells during inflammatory events through an alternative, Golgi-independent route ${ }^{1,2}$ and exerts its proinflammatory effect on endothelial cells $s^{5}$, phagocytes ${ }^{6-8}$ and lymphocytes ${ }^{9}$. Recently, it has been shown that Mrp8/14 may also be involved in the regulation of adaptive immune responses ${ }^{10}$. Several inflammatory disorders including chronic bronchitis ${ }^{11}$, inflammatory bowel disease ${ }^{12,13}$, rheumatoid arthritis ${ }^{14}$, psoriasis $^{15}$ or systemic-onset juvenile idiopathic arthritis ${ }^{16}$ are associated with elevated serum levels of MRP8/14. As a consequence, these proteins are suitable biomarkers of inflammation and are used to monitor the response towards anti-inflammatory therapy ${ }^{14,17,18}$. Interestingly, the exact function of serum-circulating MRP8/14 during an inflammatory response has remained elusive. This has also been attributed to the fact that the intracellular function of MRP8/14 may be fundamentally different to its extracellular function as an alarmin molecule ${ }^{1}$.

In inflammation, leukocyte recruitment follows a defined cascade of adhesion and activation events beginning with selectin-mediated leukocyte capture to and rolling along the inflamed endothelium ${ }^{19,20}$. This triggers intermediate activation of $\beta 2$ integrins and consecutive slowing down of the rolling leukocytes. Furthermore, rolling facilitates binding of leukocyte-expressed chemokine receptors to their cognate chemokines presented on the luminal endothelial surface. This in turn induces, together with E-selectin, binding to P-selectin glycoprotein-1 (PSGL1) and full activation of $\beta 2$ integrins ${ }^{21,22}$ leading to firm leukocyte adhesion to the endothelial surface.

Extracellular MRP8/14 is thought to influence different steps along the leukocyte recruitment process via binding to surface receptors including the Toll-like receptor-4 (TLR4) and the receptor of advanced glycation endproducts (RAGE). It has been shown that extracellular MRP8/14 induces endothelial secretion of the inflammatory chemokine CXCL8 (CXC chemokine ligand 8 also known as IL8) and upregulates Intercellular Adhesion Molecule 1 (ICAM-1) on human microvascular endothelial cells (HMECs) in vitro ${ }^{5}$. In addition, cellular permeability of MRP8/ 14-stimulated-HMEC monolayers increased ${ }^{5}$. Concerning the effect of MRP8 and MRP14 on leukocyte adhesion, Newton and Hogg showed that human MRP14 stimulates neutrophil adhesion to fibrinogen by activating the $\beta 2$ integrin Mac-1 (ref. 7). Despite recent progress regarding the function of extracellular MRP8 and MRP14 on leukocyte recruitment, the molecular mechanisms triggering the release of MRP8/14 into the extracellular compartment and the functional outcomes of such a release have remained elusive. In our study, which focused on the extracellular function of MRP8/14, we show that neutrophil rolling on E-selectin present on inflamed endothelium leads to Mrp8/14 secretion. Extracellular Mrp8/14 in turn acts in an autocrine manner through an extracellular activation loop via binding to its receptor TLR4 on neutrophils, which subsequently induces the activation of Rap1 and $\beta 2$ integrins and neutrophil slow rolling and firm arrest. Thus, we present a novel mechanism of rapid TLR4-induced $\beta 2$ integrin activation involving extracellular MRP8/14 as a modulator of leukocyte recruitment that bridges the steps of rolling and adhesion during an inflammatory response in vivo.

\section{Results}

E-selectin triggers Mrp8/14 release in vitro and in vivo. Recent studies showed that MRP8/14 was released during the interaction of activated monocytes with tumor-necrosis factor (TNF)- $\alpha$-stimulated, but not resting human umbilical vein endothelial cells (HUVECs) ${ }^{16}$. Here, we investigated which signals on the inflamed endothelium were able to induce MRP8/14 release from activated phagocytes. To this end, we isolated bone marrowderived neutrophils from C57BL/6 wild-type (WT) mice and incubated the cells at $37^{\circ} \mathrm{C}$ in wells pre-coated with E-selectin-Fc, P-selectin-Fc or PBS. Soluble phorbol myristate acetate (PMA) was used as a positive control. Supernatants were collected 10 and $30 \mathrm{~min}$ thereafter and analysed for Mrp8/14 by ELISA as described previously ${ }^{23}$. Incubation $(10 \mathrm{~min})$ of isolated neutrophils with PBS induced Mrp8/14 secretion ( $42 \pm 4 \mathrm{ng} \mathrm{ml}^{-1}$; Fig. 1a). Secretion was significantly increased in the presence of E-selectin $\left(96 \pm 13 \mathrm{ng} \mathrm{ml}^{-1}\right)$ and PMA $\left(118 \pm 12 \mathrm{ng} \mathrm{ml}^{-1}\right)$. In contrast, the presence of P-selectin failed to induce a significant increase in $\mathrm{Mrp8} / 14$ release $\left(64 \pm 11 \mathrm{ng} \mathrm{ml}^{-1}\right)$ in this assay. Addition of rat anti-mouse E-selectin antibody 9A9 inhibited E-selectin-induced Mrp8/14 release $\left(39 \pm 5 \mathrm{ng} \mathrm{ml}^{-1}\right.$; Fig. 1b). Fc control was unable to induce Mrp8/14 release $\left(30 \pm 7 \mathrm{ng} \mathrm{ml}^{-1}\right)$. Similar results were found after $30 \mathrm{~min}$ incubation (PBS: $52 \pm 8 \mathrm{ng} \mathrm{ml}^{-1}$, E-selectin: $108 \pm 17 \mathrm{ng} \mathrm{ml}^{-1}$ and P-selectin: $56 \pm 7 \mathrm{ng} \mathrm{ml}^{-1}$ ) with the exception of PMA, which further increased the release of Mrp8/14 (230 $\pm 25 \mathrm{ng} \mathrm{ml}^{-1}$; Fig. 1c).

To evaluate E-selectin involvement in Mrp8/14 secretion under in vivo conditions, we injected recombinant mouse TNF- $\alpha$ $($ rmTNF- $\alpha$ ) into the scrotum of C57BL/6 WT mice with or without intravenous (i.v.) injection of E-selectin-blocking monoclonal antibody 9A9 (30 $\mu \mathrm{g}$ per mouse) $15 \mathrm{~min}$ before rmTNF- $\alpha$ application. Mrp8/14 serum levels were measured before and $2 \mathrm{~h}$ after rmTNF- $\alpha$ treatment by ELISA. Mrp8/14 serum levels of untreated mice were $249 \pm 66$ and $273 \pm 105 \mathrm{ng} \mathrm{ml}^{-1}$, respectively. Application of rmTNF- $\alpha$ increased serum levels of Mrp8/14 to $5,590 \pm 1,013 \mathrm{ng} \mathrm{ml}^{-1}$. Pretreatment of mice with anti E-selectin blocking monoclonal antibody 9A9 significantly reduced serum levels of Mrp8/14 to 2,292 $\pm 206 \mathrm{ng} \mathrm{ml}^{-1}$, indicating that $\mathrm{E}$-selectin is involved in $\mathrm{Mrp8} / 14$ release in vivo (Fig. 1d). In a second set of experiments, we depleted neutrophils from mouse blood to prove that serum Mrp8/14 is neutrophilderived in this in vivo model. For this approach, we pretreated mice with anti-Ly6C antibody $1 \mathrm{~A} 8$ ( $30 \mu \mathrm{g}$ per mouse) $24 \mathrm{~h}$ before rmTNF- $\alpha$ treatment. Mrp8/14 serum levels of neutrophildepleted mice were $130 \pm 19 \mathrm{ng} \mathrm{ml}^{-1}$ before rmTNF- $\alpha$ treatment and $2,100 \pm 505 \mathrm{ng} \mathrm{ml}^{-1}$ after rmTNF- $\alpha$ treatment (Fig. 1d). These findings highlight that neutrophils are a central source of serum circulating Mrp8/14 under inflammatory conditions.

E-selectin-triggered Mrp8/14 release is PSGL1 dependent. Under in vivo conditions, E-selectin is known to bind to three different ligands on mouse neutrophils: PSGL1 (gene name: Selpl), CD44 and ESL1 (gene name: Glg1) ${ }^{24}$. To identify the E-selectin ligand responsible for E-selectin-triggered Mrp8/14 release, we isolated bone marrow neutrophils from $\mathrm{C} 57 \mathrm{Bl} / 6 \mathrm{WT}$, Selpl ${ }^{-1-}$ and $C d 44^{-1-}$ mice, as well as from mice with a Glg1-deficient haematopoietic system. We incubated the cells on wells coated with PBS or E-selectin for $10 \mathrm{~min}$, collected the supernatants and analysed the samples for Mrp8/14 release by ELISA as described ${ }^{23}$ (Fig. 2a). PMA was used as a positive control (Fig. 2b). Lack of CD44 did not influence the capability of cells to secrete Mrp8/14. Cd44-/- cells incubated with PBS secreted $35 \pm 3 \mathrm{ng} \mathrm{ml}^{-1} \mathrm{Mrp8} / 14$. Incubation of the cells with E-selectin increased the levels to $75 \pm 9 \mathrm{ng} \mathrm{ml}^{-1}$ (Fig. 2a). Cells from $\mathrm{Glg}^{-/-}$- and Selpl ${ }^{-/-}$-deficient mice exhibited an 
increased basal Mrp8/14 release as compared with C57BL/6 WT or $C d 44^{-/-}$cells $\left(93 \pm 40 \mathrm{ng} \mathrm{ml}^{-1}\right.$ and $97 \pm 25$, respectively). Glg1-/- -deficient cells stimulated with E-selectin showed a slight, however, not significant, increase in Mrp8/14 secretion $\left(137 \pm 37 \mathrm{ng} \mathrm{ml}^{-1}\right)$. Selpl-1- cells incubated on E-selectincoated plates were unable to increase Mrp8/14 levels as compared with levels induced by PBS $\left(110 \pm 27 \mathrm{ng} \mathrm{ml}^{-1}\right)$. These results suggest an involvement of PSGL-1 in E-selectintriggered Mrp8/14 release. Whether ESL1 may have an additional role in E-selectin-dependent secretion of $\mathrm{Mrp8} / 14$ is not entirely clear and needs further investigation. Secretion of Mrp8/14 upon PMA stimulation was not affected in

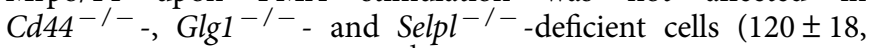
$288 \pm 65$ and $184 \pm 31 \mathrm{ng} \mathrm{ml}^{-1}$, respectively, Fig. $2 \mathrm{~b}$ ).

Released Mrp8/14 binds to TLR4 in an autocrine manner. Next, we tested the ability of released (soluble) Mrp8/14 to bind to leukocytes in an autocrine manner. For this approach, bone marrow cells from C57BL/6 WT mice were isolated and stimulated for $5 \mathrm{~min}$ at $37^{\circ} \mathrm{C}$ with or without (control) soluble E-selectin. Mrp8/14 on neutrophils was detected using a polyclonal anti-mouse Mrp14 antibody, followed by a fluorescently labelled secondary antibody. As TLR4 is considered the main cellular surface receptor of Mrp8/14 on leukocytes ${ }^{23}$, experiments were performed in the absence or presence of rat anti-mouse TLR4 antibody $1 \mathrm{~A} 6$ or IgG2b control. The amount of extracellular surface-bound Mrp14 protein on $\mathrm{Ly}_{6 \mathrm{G}}{ }^{+} / \mathrm{Mrp}_{14}{ }^{+}$ leukocytes was determined using FACS analysis. As shown in Fig. 2c, cells stimulated with E-selectin showed a $20 \%$ higher amount of Mrp14 protein (factor $1.20 \pm 0.04 \%$ ) on the cellular surface compared with control cells. Addition of anti-mouse TLR4 antibody 1A6 completely abolished the ability of released Mrp14 protein to bind to neutrophils (factor $1.01 \pm 0.06$ ), suggesting that released Mrp8/14 can bind to TLR4 in an autocrine manner. For representative FACS plots, see Supplementary Fig. 1.
MRP8/14 activates $\beta 2$ integrins via TLR4. Next, we investigated the effects of the MRP8/14-TLR4 interaction on the activation status of $\beta 2$ integrins. Owing to the lack of antibodies recognizing the activation status of $\beta 2$ integrins in mice, we performed the following experiments using human blood neutrophils where respective activation-specific antibodies are available. We enriched neutrophils from healthy blood donors and stimulated the cells for $5 \mathrm{~min}$ at $37^{\circ} \mathrm{C}$ with or without granulocytic human MRP8/14 (hMRP8/14) or lipopolysaccharide (LPS), another known TLR4 ligand. The activation status of $\beta 2$ integrins was analysed by FACS using the $\beta 2$ integrin activation markers KIM127 and mAB24 (ref. 25). Interestingly, both hMRP8/14 and LPS were able to convert $\beta 2$ integrins into an activated form. Neutrophils incubated with hMRP8/14 showed $1.38 \pm 0.08$-fold higher KIM127 antibody binding compared with control neutrophils (Fig. 3a). Incubation with LPS increased binding of KIM127 by a factor of $1.44 \pm 0.03$. To prove that measured $\beta 2$ integrin activation was indeed induced via hMRP8/14 interaction with TLR4, we pretreated human neutrophils with polyclonal rat anti-human TLR4 antibody or Paquinimod (ABR215757), respectively, before incubating the cells with hMRP8/14. Paquinimod is a small-molecule inhibitor, which blocks binding of MRP8/14 to its receptor TLR4 (refs 26,27). Both Paquinimod and polyclonal rat anti-human TLR4 antibody abolished the activation of $\beta 2$ integrins by hMRP8/14. Binding of mAB24 antibody was increased by a factor of $1.56 \pm 0.06$ and $1.96 \pm 0.1$ when cells were incubated with hMRP8/14 or LPS, respectively, as compared with control (Fig. 3b). Again, we were unable to measure $\beta 2$ integrin activation by hMRP8/14 in the presence of Paquinimod or anti-human TLR4 antibody using activationspecific mAB24 antibody (factor $1.05 \pm 0.05$ and $1.00 \pm 0.03$, respectively). For representative histogramm plots, see Supplementary Fig. 2a,b. Surface expression levels of total LFA-1 and total Mac-1 were not influenced by hMRP8/14 or by LPS (Supplementary Fig. 3a,b).

\section{b}
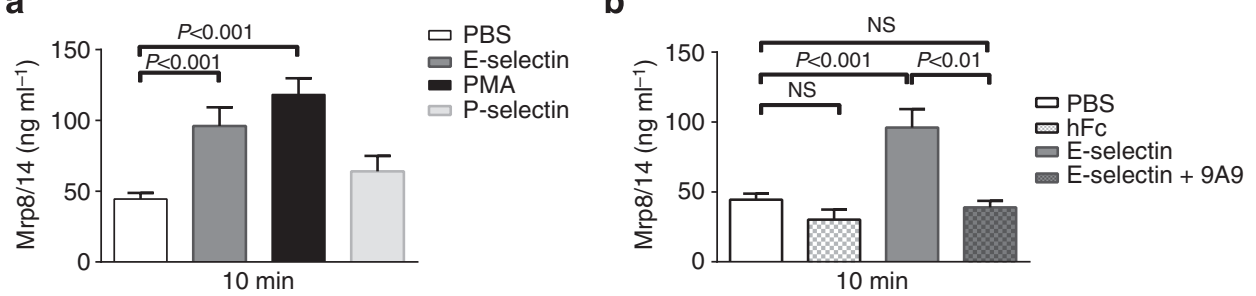

C

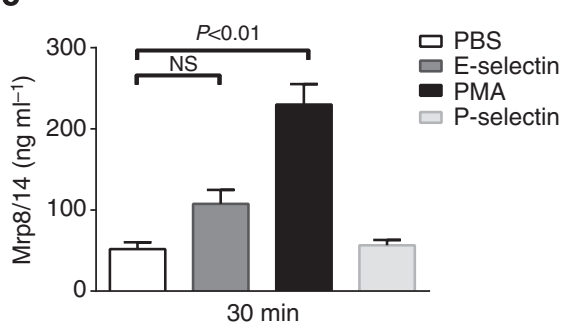

d

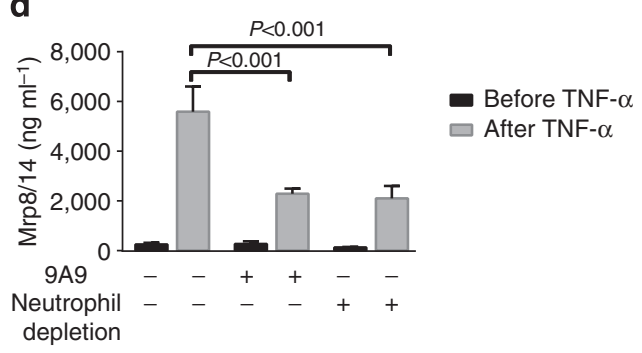

Figure 1 | Interaction of neutrophils with E-selectin results in Mrp8/14 release in vitro and in vivo. Bone marrow-derived neutrophils from C57BL/6 WT mice were incubated at $37^{\circ} \mathrm{C}$ in wells pre-coated with E-selectin, P-selectin or PBS. Soluble PMA was used as positive control. Supernatants were collected and analysed by ELISA. Mrp8/14 secretion (mean \pm s.e.m., $n \geq 5$ mice per group, one-way analysis of variance (ANOVA) with Dunnett's post-hoc test) induced by E-selectin (grey bar), PMA (black bar) and P-selectin (light grey bar) is shown after 10 min (a) and 30 min (c) incubation. (b) Mrp8/14 secretion (mean \pm s.e.m., $n \geq 3$ mice per group, one-way ANOVA with Dunnett's post-hoc test) after 10 min induced by human Fc control (white spotted bar), E-selectin (grey bar, same bar as in a) and E-selectin + anti E-selectin antibody 9A9 (grey spotted bar). PBS was used as control (white bar, same bar as in a). (d) In vivo Mrp8/14 secretion induced by E-selectin: rmTNF- $\alpha$ was injected into the scrotum of C57BL/6 WT mice without or with E-selectin blockade (9A9) and after neutrophil depletion ( $n \geq 3$ mice per group, two-way ANOVA with Tukey's post-hoc test). 


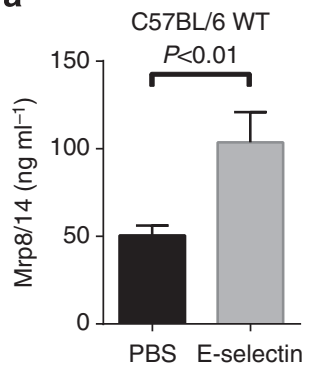

b
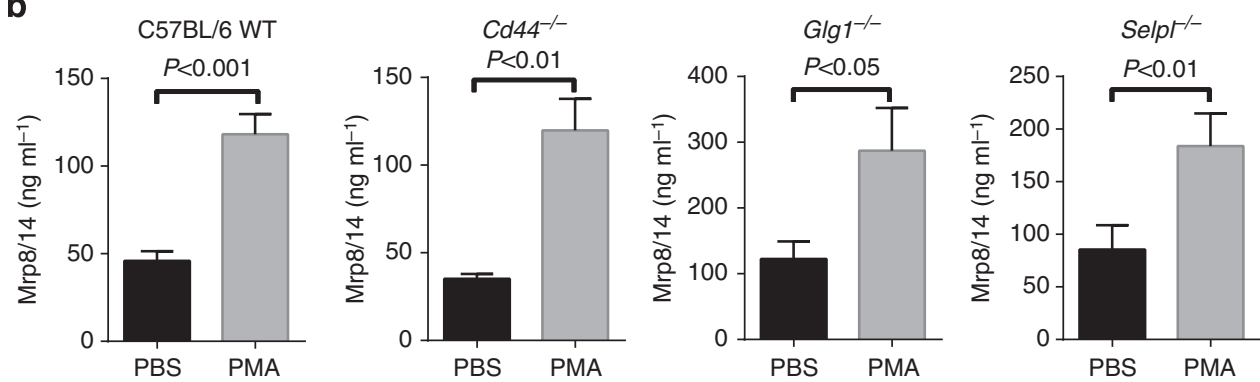

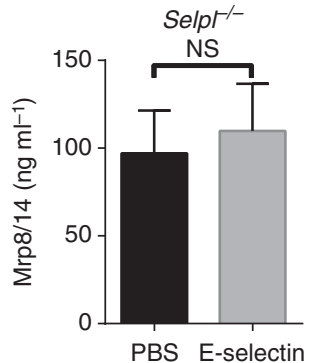

PBS E-selectin
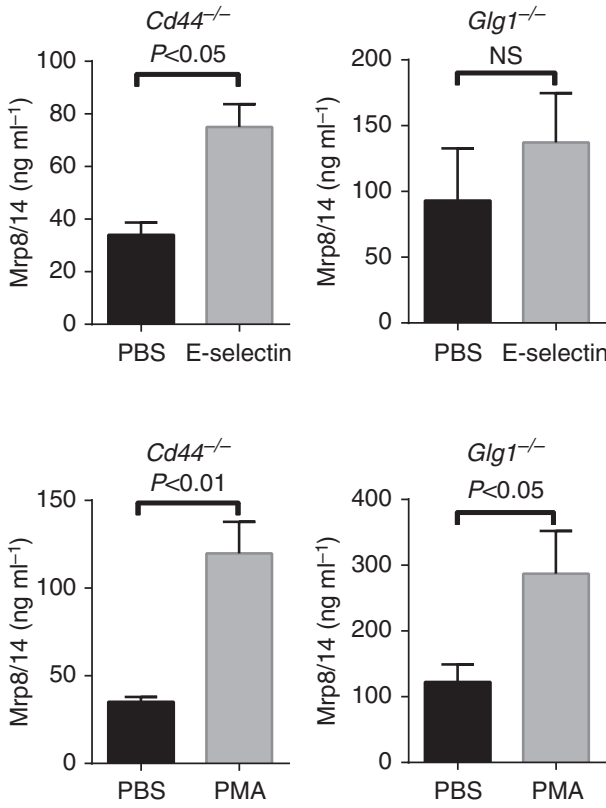

PBS E-selectin

PBS

C

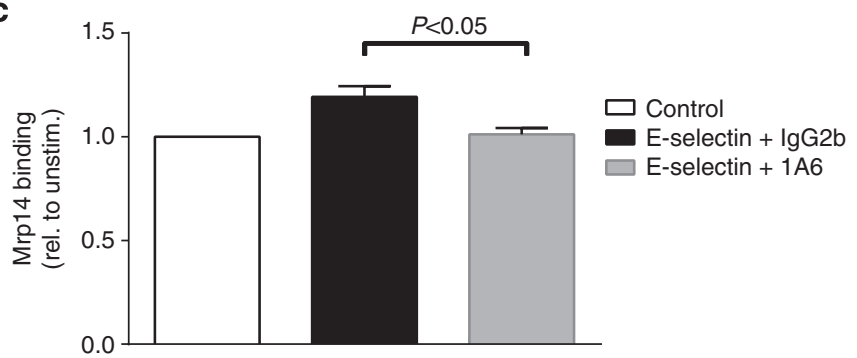


a

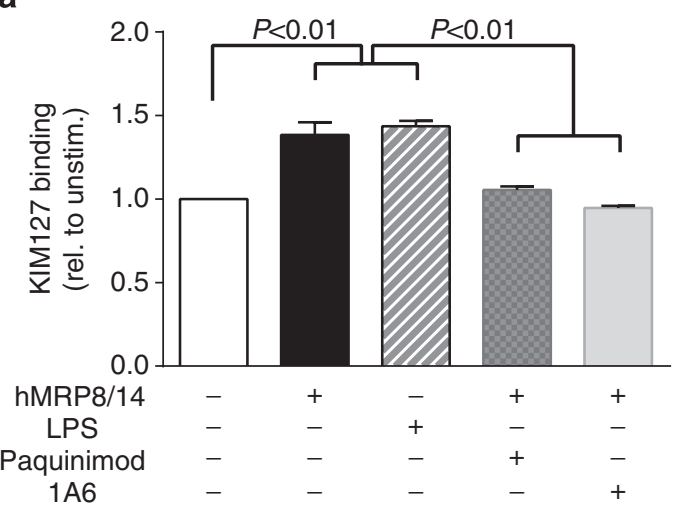

b

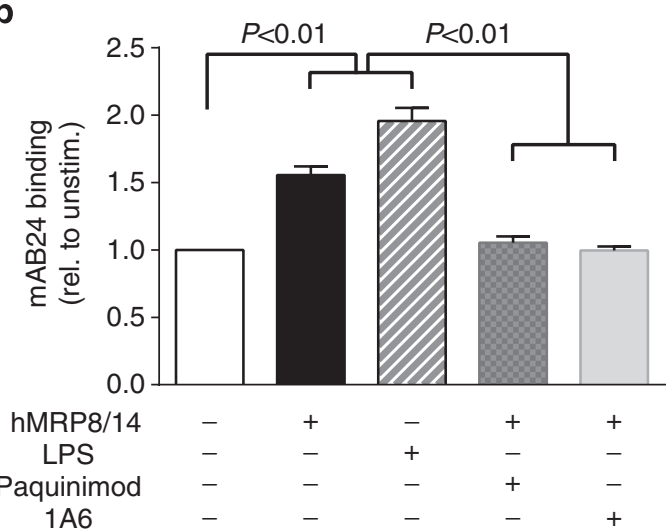

Figure 3 | MRP8/14 activates $\beta 2$ integrins via TLR4. Neutrophils from healthy blood donors were stimulated for $5 \mathrm{~min}$ at $37^{\circ} \mathrm{C}$ with or without human MRP8/14 (hMRP8/14) or LPS. In some experiments, cells were preincubated with rat anti-human polyclonal TLR4 antibody or Paquinimod. Activation status of $\beta 2$ integrins was determined using flow cytometry. Gates were set by using an isotype control. Values of KIM127 and mAB24 binding from unstimulated control was set to 1. (a) KIM127 binding and (b) mAb24 binding: control neutrophils ( $n=9$, white bar), neutrophils incubated with hMRP8/14 $(n=9$, black bar), neutrophils incubated with LPS ( $n=3$, white lined bar). Preincubation of hMRP8/14-stimulated cells with Paquinimod or polyclonal rat anti-human TLR4 antibody reduced KIM127 binding to control levels ( $n=6$, grey spotted bar and $n=3$, grey bar, respectively). Data are presented as mean \pm s.e.m., one-way analysis of variance with Tukey's post-hoc test.

investigated leukocyte rolling velocity on $\mathrm{rmE}$-selectin/rmICAM1-coated capillaries in the presence or absence of Paquinimod as well as in the presence or absence of rat anti-mouse TLR4 antibody 1A6. Addition of Paquinimod to the blood resulted in an increase in leukocyte rolling velocity to $0.51 \pm 0.04 \mu \mathrm{m} \mathrm{s}^{-1}$ (Fig. 5b). In line with this finding, the presence of anti-mouse TLR4 antibody $1 \mathrm{~A} 6$ resulted in an increase in rolling velocity to $0.51 \pm 0.02 \mu \mathrm{m} \mathrm{s}^{-1}$. Rat IgG2b isotype control did not change the rolling velocities of cells rolling on $\mathrm{rmE}$-selectin/rmICAM- 1 when compared with untreated control cells $\left(0.31 \pm 0.01 \mu \mathrm{m} \mathrm{s}^{-1}\right)$. In addition, application of Lovastatin, which has been demonstrated to keep $\beta 2$-integrins in their low-affinity status ${ }^{31}$, resulted in a mean rolling velocity of $0.57 \pm 0.05 \mu \mathrm{m} \mathrm{s}^{-1}$. Unexpectedly, whole blood cells from Tlr4-deficient mice $\left(T l r 4^{-/-}\right.$) did not show an increased rolling velocity (Fig. $5 \mathrm{c}$ ). Cells from $\mathrm{Tlr} 4^{-/}-$mice rolled with a mean rolling velocity of $0.31 \pm 0.01 \mu \mathrm{ms}^{-1}$. However, presence of Paquinimod did not influence rolling velocity of $T l r 4^{-/}$cells $\left(0.33 \pm 0.02 \mu \mathrm{m} \mathrm{s}^{-1}\right)$, indicating that slow rolling is not induced via released Mrp8/14 in Tlr4 ${ }^{-/-}$cells,

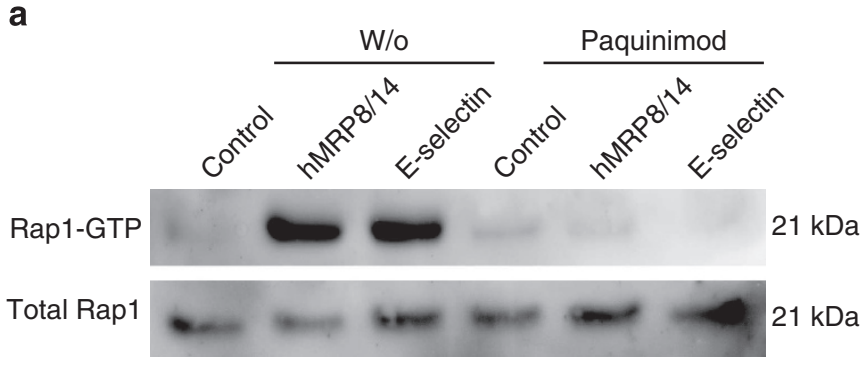

b

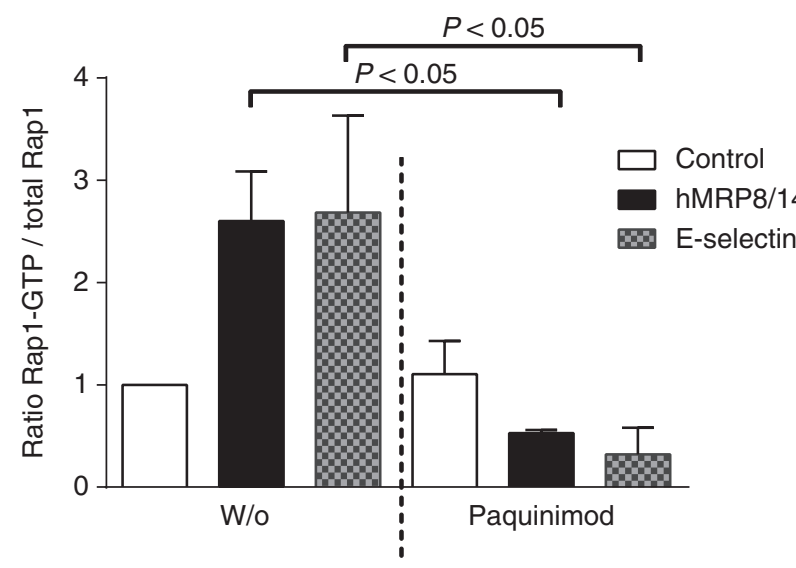

C

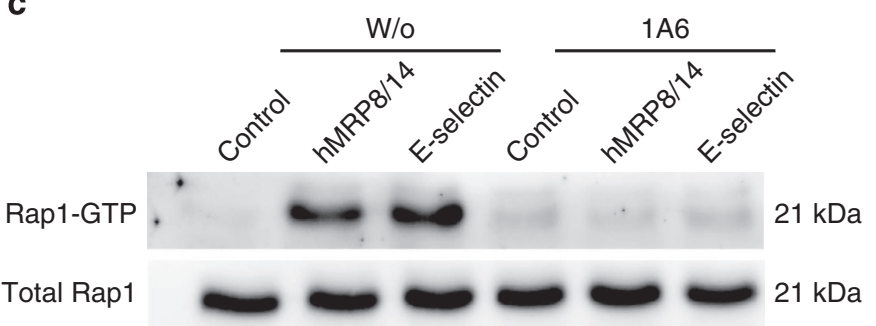

d

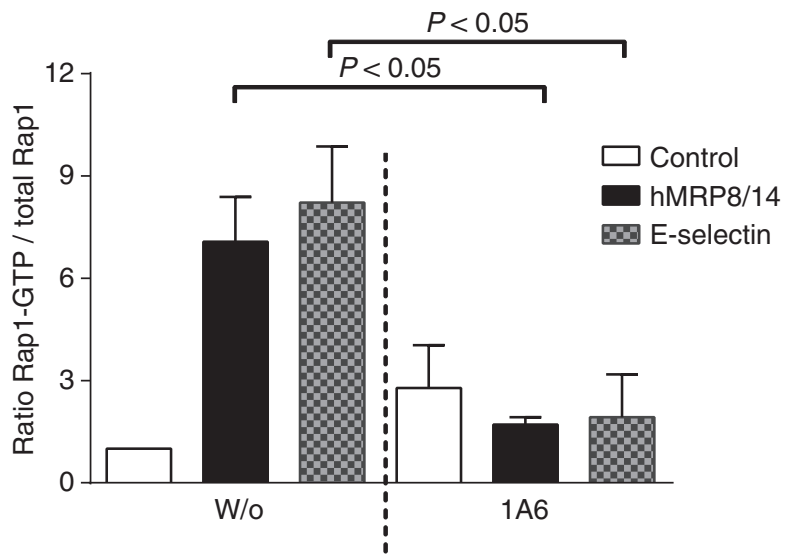

Figure 4 | MRP8/14 activates Rap1. Representative immunoblots are shown for total Rap1 and Rap1-GTP from human neutrophils stimulated with PBS/0.1\% BSA (control), human MRP8/14 (hMRP8/14) or recombinant human E-selectin (E-selectin) without (left panel, w/o) or with Paquinimod (right panel, Paquinimod; a) and without (left panel, w/o) or with rat antihuman TLR4 antibody 1A6 (right panel, 1A6; c). Density blots were calculated using Image J software (b,d). Data are presented as mean \pm s.e.m. ( $n=3$ per group, one-way analysis of variance with Dunnett's post-hoc test). 
a

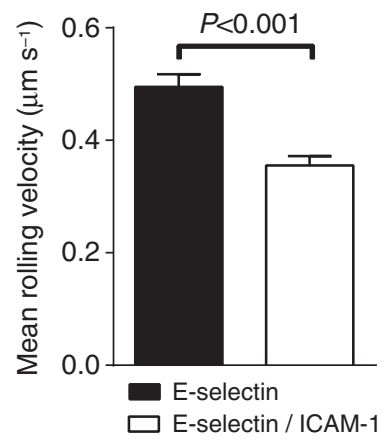

C
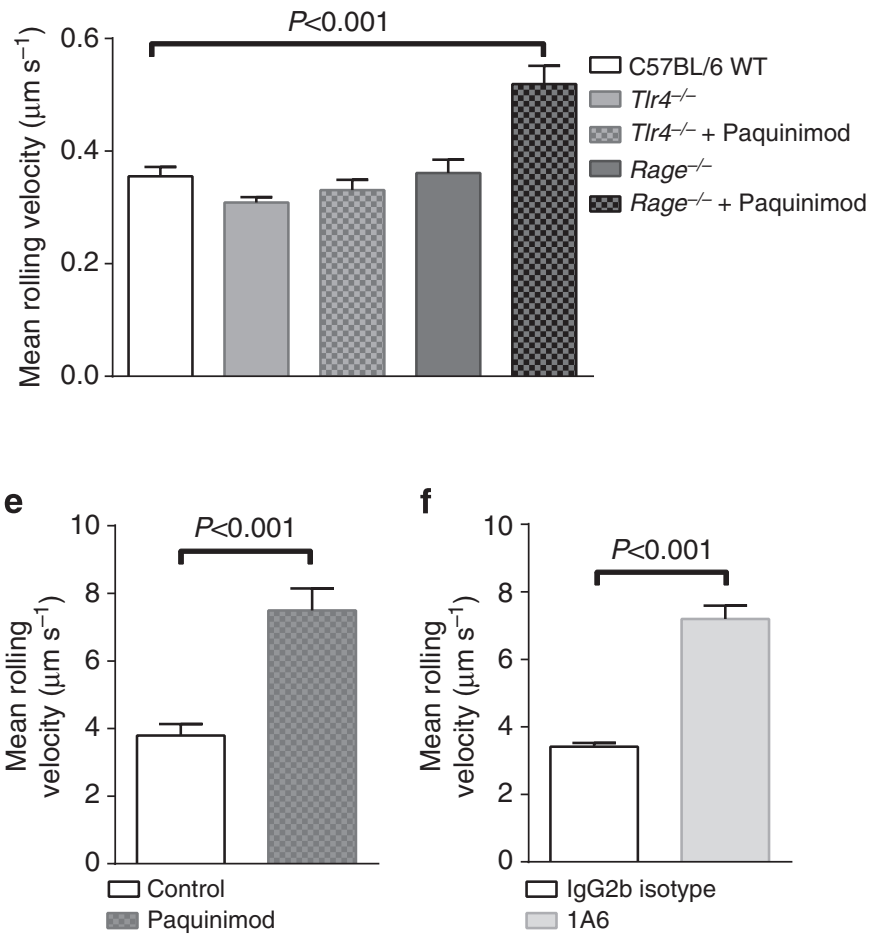

f

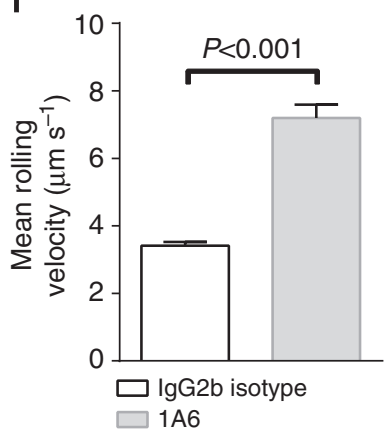

b

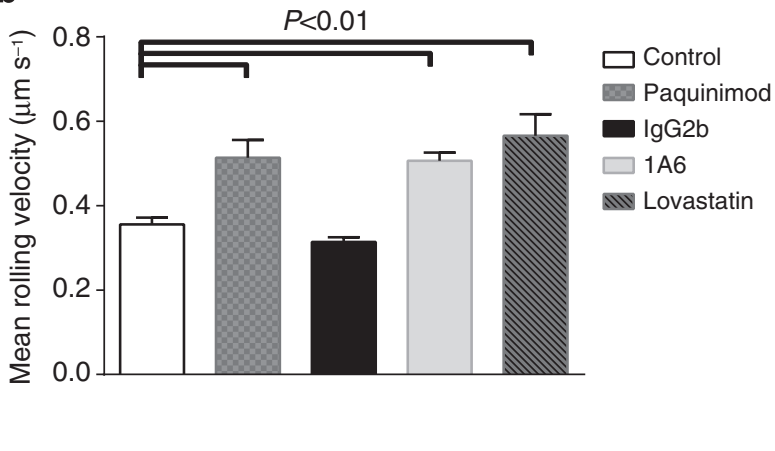

d

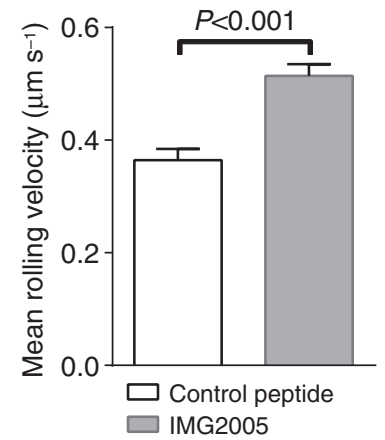

Figure 5 | Mrp8/14 reduces rolling velocity of neutrophils in vitro and in vivo. Whole mouse blood was perfused through microflow chambers (shear stress $2.7 \mathrm{dyn} \mathrm{cm}^{-2}, n \geq 3$ mice per group). (a) Leukocytes rolling velocities of C57BL/6 WT mice were assessed in rmE-selectin ( $n=209 \mathrm{cells}$ ) and rmEselectin/rmICAM-1-coated glass capillaries ( $n=178$ cells). For rmE-selectin/rmICAM-1-coated glass capillaries, leukocyte rolling velocities were assessed for (b) untreated leukocytes (white bar, same bar as in a), Paquinimod-treated leukocytes ( $n=97$ cells, grey spotted bar), rat lgG2b isotype-treated leukocytes ( $n=165$ cells, black bar), anti-TLR4 antibody 1A6-treated leukocytes ( $n=184$ cells, light grey bar) and Lovastatin-treated leukcoytes ( $n=65$ cells, grey lined bar). In addition, leukocyte rolling velocities from C57BL/6 WT mice were assessed for (c) untreated leukocytes (white bar, same bar as in $\mathbf{a}$ and $\mathbf{b}$ ), from T/r4 ${ }^{-/-}$mice for untreated leukocytes ( $n=271$ cells, grey bar) or Paquinimod treated leukocytes ( $n=182$ cells, grey spotted bar) and from Rage $^{-/-}$mice for untreated leukocytes ( $n=88$ cells, dark grey bar) or Paquinimod-treated leukocytes $(n=140$ cells, dark grey spotted bar). (d) Ex vivo leukocyte rolling velocities of cells treated with control peptide ( $n=140$ cells, white bar) or MyD88 inhibitor IMG2005 ( $n=160$ cells, grey bar) were assessed. (e) In vivo leukocyte rolling velocities were analysed in rmTNF- $\alpha$-stimulated venules of mouse cremaster muscles of C57BL/6 WT mice, pretreated with PBS/10\% DMSO as control ( $n=98$ cells, white bar) or pretreated with Paquinimod ( $n=71$ cells, grey spotted bar). (f) In addition, in vivo rolling velocity was assessed for mice pretreated with rat lgG2b isotype control $(n=225$ cells, white bar) or pretreated with rat anti-mouse TLR4 antibody $1 \mathrm{~A} 6$ ( $n=214$ cells, light grey bar). Data are presented as mean \pm s.e.m. $(\mathbf{a}, \mathbf{d}, \mathbf{e}, \mathbf{f})$ unpaired $t$-test, $(\mathbf{b}, \mathbf{c})$ one-way analysis of variance with Dunnett's post-hoc test.

but due to another, yet undefined mechanism. To also test a potential contribution of another Mrp8/14 receptor, RAGE, for Mrp8/14-induced slow leukocyte rolling velocity, we used whole blood from Rage-deficient mice $\left(\right.$ Rage $\left.^{-/-}\right)$. In contrast to $\mathrm{Tlr}^{-/-}$cells, we found leukocyte rolling velocities in Ragedeficient mice $\left(0.52 \pm 0.03 \mu \mathrm{m} \mathrm{s}^{-1}\right.$ with Paquinimod versus $0.36 \pm 0.02 \mu \mathrm{m} \mathrm{s}^{-1}$ without Paquinimod, Fig. $5 \mathrm{c}$ ), which were comparable to WT cells. These findings indicate that RAGE is not involved as relevant receptor for Mrp8/14-dependent regulation of rolling velocity. Next, we investigated potential downstream signalling molecules involved in TLR4-dependent $\beta 2$ integrin activation and slow rolling. For this approach, we pretreated C57BL/6 WT mice by intraperitoneal (i.p.) injection of either control peptide or MyD88 inhibitor IMG2005. Twenty-four hours later, a carotid artery catheter was placed and rolling velocity of leukocytes investigated via an ex vivo flow chamber system $^{29}$. Leukocytes from C57BL/6 WT mice treated with control peptide rolled at a mean rolling velocity of 
$0.32 \pm 0.01 \mu \mathrm{m} \mathrm{s}^{-1}$ (Fig. 5d). Application of IMG2005 increased rolling velocity to $0.53 \pm 0.02 \mu \mathrm{m} \mathrm{s}^{-1}$. Taken together, our results suggest that slow $\beta 2$ integrin-mediated leukocyte rolling velocity on rmE-selectin/rmICAM-1-coated capillaries is critically dependent on Mrp8/14, TLR4 and MyD88 in C57Bl/6 WT mice.

To address the in vivo relevance of our in vitro findings in the flow chamber, we used C57BL/6 WT mice and analysed leukocyte rolling velocities in $r m T N F-\alpha$-stimulated mouse cremaster muscle venules in the presence or absence of Paquinimod. Leukocyte slow rolling depends on E-selectin and the $\beta 2$ integrins LFA-1 and Mac-1 in this model, as described previously ${ }^{32}$. Mice were pretreated with Paquinimod $\left(10 \mu \mathrm{gg}^{-1}\right.$ mouse) or carrier substance (control, PBS/10\% dimethylsulphoxide (DMSO)) i.p. $1 \mathrm{~h}$ before rmTNF- $\alpha$ application. Application of Paquinimod did not affect the number of circulating leukocytes $(3,787 \pm$

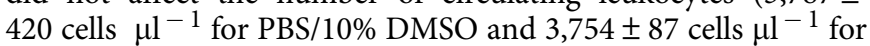
Paquinimod-treated mice, respectively). Leukocytes of control mice rolled with a mean velocity of $3.79 \pm 0.34 \mu \mathrm{m} \mathrm{s}^{-1}$ (Fig. 5e). Pretreatment of mice with Paquinimod resulted in a significant increase in rolling velocity compared with control mice with a rolling velocity of $7.50 \pm 0.65 \mu \mathrm{ms}^{-1}$. In a different set of experiments, we pretreated mice via i.p. injection of $30 \mu \mathrm{g}$ rat anti-mouse TLR4 antibody $1 \mathrm{~A} 6$ or rat IgG2b isotype control $1 \mathrm{~h}$ before rmTNF- $\alpha$ application. Cells from mice treated with rat IgG2b isotype control displayed a mean velocity of $3.41 \pm 0.12 \mu \mathrm{m} \mathrm{s}^{-1}$ (Fig. 5f). Pretreatment of mice with rat antimouse TLR4 antibody $1 \mathrm{~A} 6$ resulted in an increase in rolling velocities $\left(7.20 \pm 0.39 \mu \mathrm{m} \mathrm{s}^{-1}\right)$, which were similar to levels seen in Paquinimod-treated mice, suggesting that Mrp8/14 and its receptor TLR4 regulate leukocyte rolling velocity in vivo.

Mrp8/14 increases leukocyte adhesion in vivo. Finally, we tested the impact of Mrp8/14 on leukocyte adhesion in vivo. It was shown previously that in the TNF- $\alpha$-stimulated inflammation model of the mouse cremaster muscle, blockade of chemokineinduced inside-out signalling by pertussis toxin (PTx) resulted in a markedly reduced number of adherent cells in postcapillary venules of E-selectin $-/-\left(\right.$ Sele $\left.^{-/-}\right)$mice $^{33}$. In contrast, exclusive blocking of $\mathrm{G}_{\mathrm{i}}$-coupled chemokine receptors by PTx or exclusive lack of E-selectin did not significantly alter leukocyte adhesion in TNF- $\alpha$-stimulated cremaster muscle venules ${ }^{33}$. To demonstrate that Mrp8/14 and TLR4 are involved in E-selectintriggered leukocyte adhesion, C57BL/6 WT mice were pretreated with Paquinimod + PTx or PBS/10\% DMSO (carrier substance, control) + PTx i.p. $1 \mathrm{~h}$ before rmTNF- $\alpha$ application. In a second set of experiments, C57BL/6 WT mice were pretreated with rat anti-mouse TLR4 antibody $1 \mathrm{~A} 6+\mathrm{PTx}$ or IgG2b + PTx. RmTNF- $\alpha$ was applied to the mouse scrotum and $2 \mathrm{~h}$ later mouse cremaster muscle was dissected. Intravascular number of adherent cells per $\mathrm{mm}^{2}$ was analysed as described before ${ }^{34}$. The number of adherent cells per $\mathrm{mm}^{2}$ was significantly reduced in the presence of Paquinimod and PTx (427 \pm 36 cells $\mathrm{mm}^{-2}$, Fig. 6a), as compared with control conditions $\left(1,016 \pm 84\right.$ cells $\left.\mathrm{mm}^{-2}\right)$. Consistently, rat IgG2b isotype control + PTx did not influence the number of adherent cells per $\mathrm{mm}^{2}\left(1,088 \pm 57\right.$ cells $\left.\mathrm{mm}^{-2}\right)$, whereas the presence of $1 \mathrm{~A} 6+\mathrm{PTx}$ reduced the number of adherent cells to 500 \pm 32 cells $\mathrm{mm}^{-2}$. Representative pictures are shown in Fig. 6b, representative video clips are presented in Supplementary Movies 1 and 2. Application of Paquinimod or 1A6 alone (without PTx) did not significantly reduce the number of adherent cells per $\mathrm{mm}^{2}$ as compared with control conditions (DMSO/10\% PBS or IgG2b alone; Supplementary Fig. 5).

To exclude potential additive effects of E-selectin-induced adhesion and Mrp8/14-TLR4-induced adhesion, we additionally a

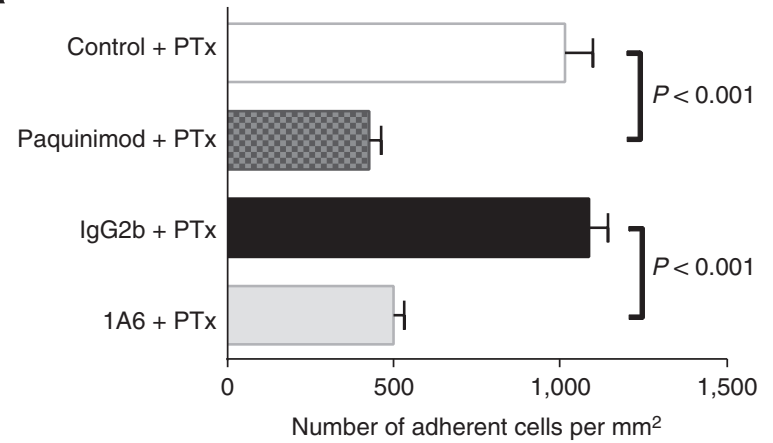

b
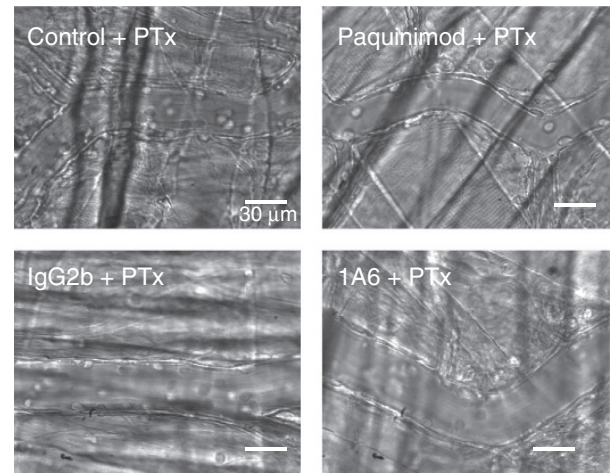

C

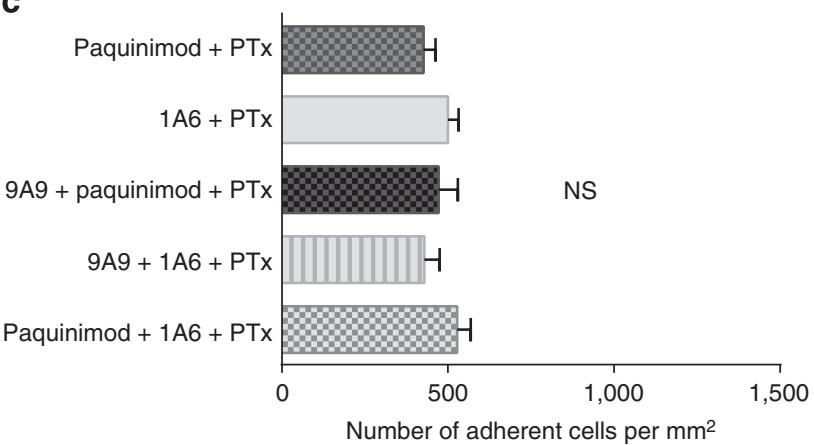

Figure 6 | Mrp8/14 increases leukocyte adhesion in TNF- $\alpha$-stimulated cremaster muscle venules in vivo. (a) C57BL/6 WT mice were pretreated with carrier substance (PBS/10\% DMSO, control) + PTx (white bar), a combination of Paquinimod + PTx (grey spotted bar), rat lgG2b isotype control + PTx (black bar) or a combination of rat anti-mouse TLR4 antibody $1 \mathrm{~A} 6+$ PTx (light grey bar). (b) One representative micrograph is shown. (c) C57BL/6 WT mice were pretreated with a combination of Paquinimod + PTx (grey spotted bar, same bar as in a), a combination of $1 A 6+$ PTx (light grey bar, same bar as in a), a combination of rat antimouse E-selectin Ab 9A9+Paquinimod + PTx (grey spotted bar), a combination of $9 A 9+1 A 6+$ PTx (light grey lined bar) or a combination of $1 \mathrm{~A} 6$ + Paquinimod + PTx (light grey spotted bar). Data are presented as mean \pm s.e.m. of at least three mice per group, one-way analysis of variance with Tukey's post-hoc test.

pretreated mice with a combination of anti-E-selectin antibody 9A9 + Paquinimod + PTx or a combination of 9A9 + 1A6 + PTx. Finally, we pretreated mice with a combination of Paquinimod + 1A6 + PTx (Fig. 6c). None of these combinations further reduced the number of adherent cells per $\mathrm{mm}^{2}$ in TNF- $\alpha$ stimulated mouse cremaster model (472 $\pm 58,429 \pm 47$ and $528 \pm 41$ cells $\mathrm{mm}^{-2}$, respectively). These findings suggest that E-selectin-triggered release of Mrp8/14 interacts with TLR4 to regulate leukocyte adhesion in vivo. 


\section{Discussion}

Leukocyte recruitment during inflammation follows a welldefined cascade of adhesion and activation events starting with tethering and rolling of leukocytes along the inflamed endothelium ${ }^{19}$. During rolling, integrins expressed on leukocytes undergo conformational changes from a low-affinity bent conformation to an intermediate and finally high-affinity open conformation leading to leukocyte slow rolling and adhesion ${ }^{35}$. Here, we present a new MRP8/14-dependent extracellular activation loop for $\beta 2$ integrin activation and hence leukocyte recruitment in vivo (illustrated in Fig. 7). We show that during E-selectin-dependent leukocyte rolling, the ligation of PSGL1 by E-selectin induces the release of Mrp8/14 complex from neutrophils. Released Mrp8/14 in turn binds to TLR4 expressed on neutrophils, which triggers the activation of Rap1 (Rap1-GTP) leading to intermediate and full-activation of $\beta 2$ integrins. Using the inhibitor Paquinimod, which blocks binding of Mrp8/14 to its receptor TLR4 (refs 26,27), we demonstrate that rapidly released Mrp8/14 and neutrophil-expressed TLR4 are a new axis for the regulation of integrin activation thereby affecting integrin-dependent steps of leukocyte recruitment, that is, slow leukocyte rolling and firm leukocyte arrest.

It has been known for several years that activated phagocytes secrete MRP8/14 during inflammatory responses via an alternative pathway bypassing the classical Golgi-route ${ }^{2}$. The secretion was described to be induced during the contact of monocytes with TNF- $\alpha$-stimulated HUVEC, but not with resting HUVEC ${ }^{16}$. Serum levels of MRP8/14, also known as calprotectin, are strongly elevated during several inflammatory processes $^{11-16}$ and the protein complex is used as an inflammatory biomarker for many years. However, the exact molecules involved in MRP8/14 release and the functional role of serum-circulating MRP8/14 during inflammation remained undefined. Previous studies have suggested that engagement of E-selectin with PSGL-1 during leukocyte rolling on inflamed endothelium triggers an intracellular signalling cascade leading to Rap1-GTP-dependent activation of $\beta 2$ integrins ${ }^{21,22,30}$, which results in leukocyte slow rolling (reviewed in ref. 22). Our study indicates that engagement of E-selectin with PSGL-1 does not directly activate Rap1-GTP and $\beta 2$ integrins, but requires an additional extracellular activation loop involving E-selectin-dependent release of Mrp8/14 with consecutive binding of extracellular Mrp8/14 to neutrophil-expressed TLR4. As PSGL-1 serves also as a ligand for P-selectin ${ }^{36}$, the other selectin expressed on inflamed endothelium, we also tested P-selectin-PSGL-1 interactions ${ }^{37}$ as trigger for Mrp8/14 release. However, we found no significant release of Mrp8/14 via P-selectin, which led us to concentrate on the E-selectin-dependent release of Mrp8/14. Previous intravital microscopy studies demonstrated that E-selectin and CXCR2 cooperate in an overlapping manner to induce firm leukocyte adhesion in TNF- $\alpha$-stimulated postcapillary venules of the mouse cremaster muscle ${ }^{33}$. Using the same mouse model, our experiments showed that blockade of $\mathrm{G} \alpha_{\mathrm{i}}$-coupled signalling through pretreatment of mice with pertussis-toxin only led to a significant drop in leukocyte adhesion, if mice were concomitantly pretreated with TLR4-blocking monoclonal antibody $1 \mathrm{~A} 6$ or Paquinimod. Additive blockade of E-selectin did not further reduce leukocyte adhesion, underlining our hypothesis that Mrp8/14-TLR4 engagement functions in the same pathway as E-selectin-PSGL1.

Of note, as MRP8/14 is only found in myeloid cells (mostly in neutrophils but also in monocytes), but not in other leukocyte subsets such as B or T lymphocytes, the described E-selectintriggered and Mrp8/14-dependent mechanism of $\beta 2$ integrin activation is restricted to the myeloid lineage and might be regarded as a specific activation signal for myeloid cell recruitment. Although mostly neutrophils contributed to the release of Mrp8/14 in our acute in vivo models, we found residual Mrp8/14 serum level in mice, where PMN were depleted. This could point to an additional release of Mrp8/14 by circulating monocytes, which have been reported to secrete Mrp8/14 under inflammatory conditions ${ }^{16}$. Furthermore, it was shown previously that Paquinimod inhibits monocyte recruitment to sides of sterile inflammation $20 \mathrm{~h}$ after immunization ${ }^{38}$.

Besides identifying an additional extracellular activation loop necessary for $\beta 2$ integrin activation during engagement of myeloid cells with the inflamed endothelial lining, another remarkable finding of this study consists in the elucidation of

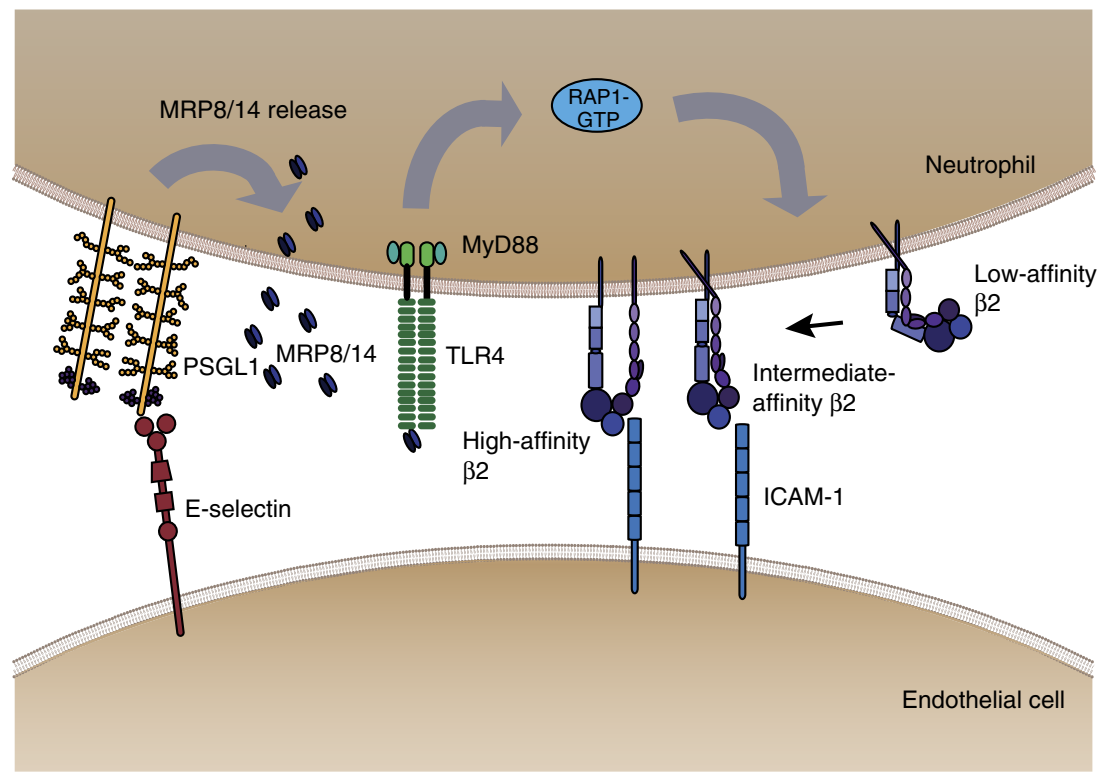

Figure 7 | Overview on MRP8/14 and its role in leukocyte recruitment in vivo. E-selectin-mediated rolling of leukocytes on inflamed endothelium triggers E-selectin-PSGL-1-dependent release of MRP8/14. Extracellular MRP8/14 in turn binds to TLR4 and through this rapid autocrine extracellular activation loop Rap1-GTP and $\beta 2$ integrin intermediate and high-affinity activation is induced, which leads to slow rolling and firm leukocyte adhesion on the inflamed endothelium. 
TLR4- signalling as a rapid inducer of $\beta 2$ integrin activation. This has not been described in vivo before and expands the function of TLR4 from its role as potent stimulator of nuclear factor- $\kappa \mathrm{B}$ to an additional component of a rapid $\beta 2$ integrin activation pathway triggered through E-selectin-dependent rolling. Signalling via TLR4 is complex, as many different ligands exist, which are able to cause different cellular responses due to the recruitment/ activation of different adaptor/signalling molecules downstream of TLR4. In the case of Mrp8/14, ligation of TLR4 by Mrp8/14 induces wide-ranging effects on neutrophils. This includes cytokine and chemokine production, generation of reactive oxygen species ${ }^{1}$ and, as shown here, rapid $\beta 2$ integrin activation. However, how MRP8/14-stimulated TLR4 signalling pathways induce $\beta 2$ integrin activation is currently not entirely understood. We identified the involvement of MyD88 and Rap1GTP downstream of TLR4 stimulation. Interestingly, when we analysed the rolling behaviour of Tlr4 $4^{-/-}$leukocytes, rolling velocities in flow chambers coated with rmE-selectin and rmICAM-1 were equal to those found in C57BL/6 WT mice. Similarly, Andonegui and colleagues reported that leukocyte rolling velocities in TNF- $\alpha$-treated cremaster muscle venules were similar between WT and Tlr4 ${ }^{-1-}$ mice $^{37}$. However, the same study also reported that in contrast to WT mice, in which local LPS treatment led to a significant drop in leukocyte rolling velocities, leukocyte rolling velocities in $\mathrm{Tlr}^{-1-}$ mice did not significantly change over baseline following local stimulation with LPS $^{37}$. This implies that TLR4 is involved in regulating leukocyte rolling velocities. However, the involvement of TLR4 does not seem to be constitutive, but rather ligation/stimulation dependent. This could be an explanation for the masking of the leukocyte rolling velocity response in $T l r 4^{-/-}$mice. Future studies will be necessary to further clarify this issue and work out the precise signalling pathway of TLR4-dependent $\beta 2$ integrin activation in neutrophils and monocytes.

MRP8/14 can also bind to other receptors such as the RAGE $^{39,40}$ and Paquinimod can also affect the binding of MRP14 to RAGE ${ }^{26}$. Therefore, we also tested a potential involvement of neutrophil-expressed RAGE on Mrp8/14 effector functions. Interestingly, our own Mrp8/14 release studies showed that stimulated Mrp8/14 release led only to an increase in neutrophil surface binding of Mrp8/14 in the presence of TLR4. These results indirectly speak against a role of neutrophil-expressed RAGE as relevant Mrp8/14 ligand in terms of $\beta 2$ integrin activation. Furthermore, we found that blockade of Mrp8/14 binding to TLR4 with Paquinimod increased Rage ${ }^{-7-}$ neutrophil rolling velocity to the same extent as seen in C57BL/6 WT mice suggesting no role of neutrophil-expressed RAGE in regulating Mrp8/14-dependent slow leukocyte rolling.

TLR4 and other MRP8/14-binding molecules are also expressed on inflamed endothelial cells and it was shown that MRP8/14 induces a thrombogenic, inflammatory response in HMEC cells in vitro ${ }^{5}$. The transcription of proinflammatory chemokines like IL8 and proinflammatory molecules like ICAM1 was increased upon MRP8/14 treatment of HMEC cells. We show reduced adhesion of leukocytes on inflamed endothelium in C57BL/6 WT mice pretreated with a combination of Paquinimod and PTx or a combination of anti-TLR4 antibody 1A6 and PTx. Although our in vitro assays indicate that MRP8/14 exerts its proinflammatory function via binding to TLR4 on neutrophils, MRP8/14 binding to the inflamed endothelium may also contribute to leukocyte recruitment during inflammation in vivo.

In summary, our results revise and expand our view on the molecular mechanisms governing leukocyte recruitment during inflammation by introducing a novel MRP8/14-dependent extracellular activation loop as a modulator of the recruitment process in vivo (Fig. 7) via bridging the rolling and adhesion processes in an autocrine manner. MRP8/14 released from neutrophils by E-selectin-PSGL1 interactions binds to TLR4, which in turn stimulates a rapid signal transduction cascade leading-via MyD88 and Rap1-GTP-to $\beta 2$ integrin activation, a necessary step for the induction of slow leukocyte rolling and firm arrest on inflamed endothelium.

\section{Methods}

Animals. $C d 44^{-/-}$mice were provided by Rodger P. McEver (Cardiovacular Biology Research Program, Oklahoma, OK, USA $)^{41}$. Selpl $l^{-/-}$and $\mathrm{Glg}^{-/-}$mice were provided by Dietmar Vestweber (Max Planck Institute for Biochemistry, Münster, Germany) ${ }^{24,36}$. Tlr $4^{-/-}$mice were obtained from Admar Verschoor (University of Munich, Germany) ${ }^{42}$. Rage $e^{-/-}$mice were provided by Angelika Bierhaus (University of Heidelberg, Germany, deceased) and Peter Nawroth (University of Heidelberg, Germany) ${ }^{43}$. All mice strains had been backcrossed into C57BL/6 WT background. Glg1 $1^{-1}-$ mice are embryonically lethal. Therefore, fetal liver cell chimeras (named Glg1-/ ${ }^{-1}$ mice) were generated as described ${ }^{44}$ using Glg1-deficient fetal liver cells adoptively transferred into lethally irradiated C57Bl/6 WT mice. C57BL/6 WT mice were obtained from the Janvier Labs (Saint Berthevin, France). All mice were maintained at the Walter Brendel Center for Experimental Medicine, Ludwig Maximilians Universität, Munich, Germany. Eight- to twenty-week-old male mice were used for all experiments. Animal experiments were approved by the government Oberbayern, Germany, AZ 55.2-154-2531-134/08, -175/09, $-90 / 09$ and $-76 / 12$.

Mrp8/14 release assay. For the in vitro release assay, we coated glass dishes overnight with rmE-selectin (CD62E Fc chimera, R\&D Systems, $10 \mu \mathrm{g} \mathrm{ml}^{-1}$ ), rmP-selectin (CD62P Fc chimera, R\&D $10 \mu \mathrm{g} \mathrm{ml}^{-1}$ ), FcR (Miltenyi Biotec $\mathrm{GmbH}$, $10 \mu \mathrm{g} \mathrm{ml}^{-1}$ ) or PBS at $4^{\circ} \mathrm{C}$. Bone marrow-derived neutrophils were isolated from C57BL/6 WT, Selpl ${ }^{-/-}, C_{444^{-/-}}$and $G l g 1^{-/-}$mice using EasySep mouse neutrophil enrichment kit (STEMCELL TECHNOLOGIES) according to the manufacturer's protocol. Purity of isolated cells was over $90 \%$. Glass dishes were transferred into a 24-well plate, blocked with 5\% Casein (Sigma-Aldrich) for $2 \mathrm{~h}$ and washed with PBS. $5 \times 10^{5}$ neutrophils were reconstituted in HBSS buffer (HBSS containing $1 \mathrm{mM} \mathrm{CaCl}$ und $1 \mathrm{mM} \mathrm{MgCl}_{2}, 10 \mathrm{mM} \mathrm{HEPES,} \mathrm{0.25 \%} \mathrm{BSA,}$ $0.1 \%$ Glucose, $\mathrm{pH} 7.4$ ) and incubated under shaking conditions on the pre-coated wells at $37^{\circ} \mathrm{C}$ for 10 or $30 \mathrm{~min}$. Soluble PMA (Sigma-Aldrich, $1 \mu \mathrm{M}$ ) was used as positive control. Rat anti-mouse E-selectin antibody 9A9 (kind gift from Dr Barry Wolitzky, MitoKor, $10 \mu \mathrm{g} \mathrm{ml}^{-1}$ ) was used to block E-selectin-induced Mrp8/14 release. Supernatants were collected and analysed by ELISA to determine the concentrations of Mrp8/14 as described earlier ${ }^{23}$

For the in vivo release assay, we injected rmTNF- $\alpha$ (R\&D Systems, $500 \mathrm{ng}$ per mouse) into the scrotum of C57BL/6 WT mice, as described earlier ${ }^{34}$. Blocking experiments were performed by i.v. injection of rat anti-mouse antibody 9A9 (30 $\mu$ g per mouse) 15 min before rmTNF- $\alpha$ application. Neutrophil depletion was induced via i.v. injection of $30 \mu \mathrm{g}$ rat anti-mouse Ly6G antibody (BioLegend, 1A8) $22 \mathrm{~h}$ before rmTNF- $\alpha$ application. $100 \mu \mathrm{l}$ of mouse blood was collected via retroorbital bleeding before application of anti-mouse E-Selectin antibody or/and rmTNF- $\alpha$ and $2 \mathrm{~h}$ after rmTNF- $\alpha$ application. Serum was separated using Microtainer SST Tubes columns (REF 365951, Becton \& Dickinson BD) according to the manufacturer's protocol and ELISA was used to determine the concentration of Mrp8/14 as described earlier ${ }^{23}$.

Autocrine MRP8/14 binding to neutrophils. Bone marrow cells were isolated from C57BL/6 WT mice. $1 \times 10^{6}$ cells were stimulated for $5 \mathrm{~min}$ at $37^{\circ} \mathrm{C}$ with PBS/ $0.1 \%$ BSA or soluble rmE-Selectin (CD62E Fc chimera, R\&D Systems, $1 \mu \mathrm{g} \mathrm{ml}^{-1}$ ). Rat IgG2b isotype control (eBioscience, $10 \mu \mathrm{g} \mathrm{ml}^{-1}$ ) or rat anti-mouse TLR4 antibody (1A6, NovImmune SA, $10 \mu \mathrm{g} \mathrm{ml}^{-1}$ ) were co-incubated with tubes containing soluble rmE-selectin. Cells were fixed using BD FACS Lysing solution (BD) and washed with PBS/5\% BSA. Thereafter, cells were stained with polyclonal rabbit anti-mouse Mrp14 antibody $\left(1.5 \mu \mathrm{g} \mathrm{ml}^{-1}\right.$, Johannes Roth, University of Münster). Donkey anti-rabbit Alexa Flour 488 (Molecular Probes/Invitrogen, $2.5 \mu \mathrm{g} \mathrm{ml}^{-1}$ ) was used as secondary antibody. Rat anti-mouse Ly6G pacific blue (1A8, BioLegend, $1 \mu \mathrm{g} \mathrm{ml}^{-1}$ ) was used to define neutrophils. Amount of receptorbound Mrp14 on Ly6G ${ }^{+} / \mathrm{Mrp}_{14}{ }^{+}$cells was determined using a Beckman Coulter Gallios flow cytometer.

及2 Integrin activation assay. Human neutrophils were isolated from healthy volunteer blood donors using Polymorphoprep (AXI-SHIELD PoC AS). Enriched neutrophils $\left(5 \times 10^{5}\right.$ sample $\left.^{-1}\right)$ were preincubated with Paquinimod (Active Biotech AB, $10 \mu \mathrm{g} \mathrm{ml}^{-1}$ ), PBS/10\% DMSO (carrier substance), rat anti-human polyclonal TLR4 (PAb-hTLR4, Invivogen, $1 \mu \mathrm{g} \mathrm{ml}^{-1}$ ) or normal rat IgG Isotype (EMFRET Analytics \& Co., $1 \mu \mathrm{g} \mathrm{ml}^{-1}$ ) for $3 \mathrm{~min}$ at $37^{\circ} \mathrm{C}$, respectively. hMRP8/14 was obtained from Johannes Roth, University of Münster. The complex was prepared essentially free of endotoxin contamination from human neutrophils as previously described ${ }^{45}$. hMRP8/14 $\left(5 \mu \mathrm{g} \mathrm{ml}^{-1}\right)$, LPS (Sigma-Aldrich, $1 \mu \mathrm{g} \mathrm{ml}^{-1}$ ), 
PMA (Sigma-Aldrich, $1 \mu \mathrm{M}$ ) or PBS/0.1\% BSA were added to vials containing mouse anti-human $\beta 2$ integrin activation antibody KIM127 (Invivo, $10 \mu \mathrm{g} \mathrm{ml}^{-1}$ ) or mAB 24 (Hycult Biotech, $10 \mu \mathrm{g} \mathrm{ml}^{-1}$ ) or IgG1 Isotype control antibody (BioLegend, $10 \mu \mathrm{g} \mathrm{ml}^{-1}$ ) and warmed up to $37^{\circ} \mathrm{C}$ for $5 \mathrm{~min}$. Preincubated neutrophils and pre-warmed substance/antibody mix were pooled. Cells were stimulated for another $5 \mathrm{~min}$ at $37^{\circ} \mathrm{C}$ in a total volume of $40 \mu$ l. Reaction was stopped by adding $900 \mu \mathrm{l}$ ice-cold BD FACS Lysing solution (BD) and tubes were immediately transferred on ice. After 10 min fixation time, cells were washed and stained with goat anti-mouse PE antibody (BD Biosciences Pharmingen,

$2.5 \mu \mathrm{g} \mathrm{ml}^{-1}$ ). To define human neutrophils, cells were finally stained with mouse anti-human CD15-FITC (VIMC6, Miltenyi Biotec GmbH, 1:100) and mouse antihuman CD66abce-APC (TET2, Miltenyi Biotec GmbH, 1:100). Activation status of $\beta 2$ integrins was determined using a Beckman Coulter Gallios flow cytometer. In a second set of experiments, total Mac-1 and total LFA-1 protein amount was investigated. For this approach, mouse anti-human CD11b (ICRF44, BioLegend, $5 \mu \mathrm{g} \mathrm{ml}^{-1}$ ) or mouse anti-human CD11a (HI111, BD Biosciences Pharmingen, $5 \mu \mathrm{g} \mathrm{ml}^{-1}$ ) was used.

Rap1 activation assay. Human neutrophils were isolated from healthy volunteer blood donors using a double gradient with Histopaque-1119 and 1077 (SigmaAldrich). To assess active Rap1 in human neutrophils, a pull-down assay was performed with Rap1 Activation Kit (Milipore) according to the manufacturer's instructions. Briefly, $4 \times 10^{6}$ human neutrophils were incubated or not with E-selectin $\left(1 \mu \mathrm{g} \mathrm{ml}^{-1}\right)$ or hMRP8/14 $\left(5 \mu \mathrm{g} \mathrm{ml}^{-1}\right)$ at $37^{\circ} \mathrm{C}$ for $5 \mathrm{~min}$ in complete RPMI medium. For inhibitor experiments, cells were pretreated with Paquinimod $\left(10 \mu \mathrm{g} \mathrm{ml}^{-1}\right)$ or rat anti-human TLR4 antibody $\left(1 \mu \mathrm{g} \mathrm{ml}^{-1}\right)$ for $2 \mathrm{~min}$ before adding E-selectin or hMRP8/14. Ral GDS-RBD agarose (Milipore, $25 \mu \mathrm{l}$ ) was added to each cell extract and incubated for $50 \mathrm{~min}$ at $4{ }^{\circ} \mathrm{C}$. Precipitates were then washed, re-suspended in $30 \mu \mathrm{l}$ of $\times 2$ sample buffer, boiled for $10 \mathrm{~min}$ at $95^{\circ} \mathrm{C}$ and separated by $12 \%$ SDS-PAGE. Rabbit Rap1 antibody (Milipore, $1 \mu \mathrm{g} \mathrm{ml}^{-1}$ ) was used to detect active Rap1 (Rap1-GTP). Whole-cell lysates $(10 \mu \mathrm{l})$ from each cell extract before adding agarose were used to assess total levels of Rap1. The band intensity was quantified by using the Image J software $(\mathrm{NIH})^{46}$. Blood drawing for isolation of human neutrophils from healthy human volunteers was performed with informed consent and approved by the local ethics committee at the University of Dresden, Germany.

In vitro and ex vivo flow chamber. To investigate rolling velocities, we used a previously described flow chamber system ${ }^{29}$. Glass capillaries (Rect. Boro Capillaries $0,04 \times 0,40 \mathrm{~mm} \mathrm{ID}$, VitroCom) were coated overnight with rmE-selectin (CD62E Fc chimera, R\&D Systems, $20 \mu \mathrm{g} \mathrm{ml}^{-1}$ ) or a combination of rmE-Selectin and rmICAM-1 (ICAM-1 Fc chimera, R\&D Systems, $15 \mu \mathrm{g} \mathrm{ml}^{-1}$ ) and blocked with $5 \%$ casein (Sigma-Aldrich) for $2 \mathrm{~h}$. Whole blood was collected from C57BL/6 WT, Rage ${ }^{-/-}$or Tlr $4^{-/-}$mice via the carotid artery and heparinized. Depending on the desired condition, Paquinimod (Active Biotech $\mathrm{AB}, 10 \mu \mathrm{g} \mathrm{ml}{ }^{-1}$ ), rat IgG2b (BD Biosciences Pharmingen, $10 \mu \mathrm{g} \mathrm{ml}^{-1}$ ), rat anti-mouse TLR4 antibody 1A6 (1A6, NovImmune SA, $10 \mu \mathrm{g} \mathrm{ml}^{-1}$ ) or Lovastatin (Calbiochem, Merck KGaA, $100 \mu \mathrm{M})$ was added to the blood sample, respectively. Samples were preincubated for $3 \mathrm{~min}$ at $35^{\circ} \mathrm{C}$ and perfused through the microflow chambers using a high

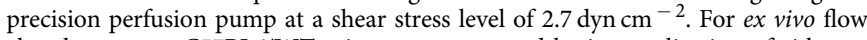
chamber assays, C57BL6/WT mice were pretreated by i.p. application of either control peptide (BIOMOL, $1 \mathrm{mg} \mathrm{kg}^{-1}$ ) or MyD88 inhibitor IMG2005 (BIOMOL, $1 \mathrm{mg} \mathrm{kg}^{-1}$ ) for $24 \mathrm{~h}$. Carotid artery catheter was placed and mouse blood directly perfused through the microflow chamber at a shear stress level of 3-4 dyn $\mathrm{cm}^{-2}$. One representative field was recorded for 5 min using an Olympus BX51WI microscope with a CCD camera (model CF8/1, Kappa) and a water immersion objective (x40/0.8 NA, Olympus). Rolling velocity of the cells was determined using Fiji software ${ }^{46}$.

TNF- $\alpha$-induced inflammation model of mouse cremaster muscle. The TNF- $\alpha-$ induced inflammation model of the mouse cremaster muscle was performed as described previously in C57BL/6 WT mice ${ }^{34}$. Briefly, C57BL/6 WT mice were pretreated i.p. with a combination of Paquinimod (Active Biotech AB, $10 \mathrm{mg} \mathrm{kg}^{-1}$ ) + PTx (Sigma-Aldrich, $4 \mu \mathrm{g}$ per mouse) or rat anti-mouse TLR4 antibody (1A6, NovImmune SA, $100 \mu \mathrm{g}$ per mouse) + PTx (Sigma-Aldrich, $4 \mu \mathrm{g}$ per mouse). PBS/10\%DMSO (carrier substance) + PTx and rat IgG2b (eBioscience, $100 \mu \mathrm{g}$ per mouse) + PTx were used as controls, respectively. In a second set of experiments, rat anti-mouse anti-E-selectin antibody 9A9 (100 $\mu \mathrm{g}$ per mouse) was applied concomitantly. Depending on the desired condition and for the investigation of in vivo rolling velocities, Paquinimod, $\mathrm{PBS} / 10 \% \mathrm{DMSO}, 1 \mathrm{~A} 6$ and rat IgG2b isotype control were applied without PTx. $500 \mathrm{ng}$ of rmTNF- $\alpha$ (R\&D Systems, $500 \mathrm{ng}$ mouse ${ }^{-1}$ ) was applied to the mouse scrotum $1 \mathrm{~h}$ later. After $2 \mathrm{~h}$ of rmTNF- $\alpha$ application, cremaster muscle was dissected. Mean rolling velocities and number of adherent cells per mm were determined using intravital microscopy (Olympus BX51WI microscope, water immersion objective x20, 0.95 numerical aperture, Olympus). All scenes were recorded using a CCD camera (model CF8/1, Kappa) and virtual dub software for later off-line analysis. During the entire observation, the cremaster muscle was superfused with thermo-controlled $\left(35^{\circ} \mathrm{C}\right)$ bicarbonate-buffered saline. Postcapillary venules under observation ranged from
20 to $40 \mu \mathrm{m}$ in diameter. Microvascular parameters (venular diameter, venular vessel segment length) were determined using Fiji software ${ }^{46}$.

Statistical analyses. All data were analysed and plotted using Graph Pad Prism 6.05 Software (GraphPad Software Inc.). For pairwise comparison of experimental groups, a paired $t$-test was performed. Depending on the condition, we used oneway analysis of variance with either Dunnett's post-hoc test (comparison of experimental groups against control) or Tukey's post-hoc test (comparison of all experimental groups against each other) or a two-way analysis of variance with Tukey's post-hoc test (comparison of paired experimental groups against each other) for multiple comparison. $P$-values $<0.05$ were considered statistically significant.

\section{References}

1. Ehrchen, J. M., Sunderkotter, C., Foell, D., Vogl, T. \& Roth, J. The endogenous Toll-like receptor 4 agonist S100A8/S100A9 (calprotectin) as innate amplifier of infection, autoimmunity, and cancer. J. Leukoc. Biol. 86, 557-566 (2009).

2. Foell, D., Wittkowski, H., Vogl, T. \& Roth, J. S100 proteins expressed in phagocytes: a novel group of damage-associated molecular pattern molecules. J. Leukoc. Biol. 81, 28-37 (2007).

3. Vogl, T., Gharibyan, A. L. \& Morozova-Roche, L. A. Pro-inflammatory S100A8 and S100A9 proteins: self-assembly into multifunctional native and amyloid complexes. Int. J. Mol. Sci. 13, 2893-2917 (2012).

4. Edgeworth, J., Gorman, M., Bennett, R., Freemont, P. \& Hogg, N. Identification of $\mathrm{p} 8,14$ as a highly abundant heterodimeric calcium binding protein complex of myeloid cells. J. Biol. Chem. 266, 7706-7713 (1991).

5. Viemann, D. et al. Myeloid-related proteins 8 and 14 induce a specific inflammatory response in human microvascular endothelial cells. Blood 105, 2955-2962 (2005).

6. Ryckman, C., Vandal, K., Rouleau, P., Talbot, M. \& Tessier, P. A. Proinflammatory activities of S100: proteins S100A8, S100A9, and S100A8/A9 induce neutrophil chemotaxis and adhesion. J. Immunol. 170, 3233-3242 (2003).

7. Newton, R. A. \& Hogg, N. The human S100 protein MRP-14 is a novel activator of the beta 2 integrin Mac-1 on neutrophils. J. Immunol. 160, 1427-1435 (1998).

8. Vogl, T. et al. MRP8 and MRP14 control microtubule reorganization during transendothelial migration of phagocytes. Blood 104, 4260-4268 (2004).

9. Loser, K. et al. The Toll-like receptor 4 ligands Mrp8 and Mrp14 are crucial in the development of autoreactive CD8 + T cells. Nature Med. 16, 713-717 (2010).

10. Petersen, B. et al. The alarmin Mrp8/14 as regulator of the adaptive immune response during allergic contact dermatitis. EMBO J. 32, 100-111 (2013).

11. Roth, J. et al. Complex pattern of the myelo-monocytic differentiation antigens MRP8 and MRP14 during chronic airway inflammation. Immunobiology 186, 304-314 (1992).

12. Lugering, N. et al. Immunohistochemical distribution and serum levels of the $\mathrm{Ca}(2+)$-binding proteins MRP8, MRP14 and their heterodimeric form MRP8/14 in Crohn's disease. Digestion 56, 406-414 (1995).

13. Tibble, J. A. \& Bjarnason, I. Non-invasive investigation of inflammatory bowel disease. World J. Gastroenterol. 7, 460-465 (2001).

14. Brun, J. G., Jonsson, R. \& Haga, H. J. Measurement of plasma calprotectin as an indicator of arthritis and disease activity in patients with inflammatory rheumatic diseases. J. Rheumatol. 21, 733-738 (1994).

15. Schonthaler, H. B. et al. S100A8-S100A9 protein complex mediates psoriasis by regulating the expression of complement factor C3. Immunity 39, 1171-1181 (2013).

16. Frosch, M. et al. Myeloid-related proteins 8 and 14 are specifically secreted during interaction of phagocytes and activated endothelium and are useful markers for monitoring disease activity in pauciarticular-onset juvenile rheumatoid arthritis. Arthritis Rheum. 43, 628-637 (2000).

17. Foell, D., Frosch, M., Sorg, C. \& Roth, J. Phagocyte-specific calcium-binding S100 proteins as clinical laboratory markers of inflammation. Clin. Chim. Acta 344, 37-51 (2004).

18. Lugering, N. et al. The myeloic related protein MRP8/14 (27E10 antigen)-usefulness as a potential marker for disease activity in ulcerative colitis and putative biological function. Eur. J. Clin. Invest. 25, 659-664 (1995).

19. Ley, K., Laudanna, C., Cybulsky, M. I. \& Nourshargh, S. Getting to the site of inflammation: the leukocyte adhesion cascade updated. Nat. Rev. Immunol. 7 , 678-689 (2007).

20. Kolaczkowska, E. \& Kubes, P. Neutrophil recruitment and function in health and inflammation. Nat. Rev. Immunol. 13, 159-175 (2013).

21. Zarbock, A., Lowell, C. A. \& Ley, K. Spleen tyrosine kinase Syk is necessary for E-selectin-induced alpha(L)beta(2) integrin-mediated rolling on intercellular adhesion molecule-1. Immunity 26, 773-783 (2007).

22. Zarbock, A., Ley, K., McEver, R. P. \& Hidalgo, A. Leukocyte ligands for endothelial selectins: specialized glycoconjugates that mediate rolling and signaling under flow. Blood 118, 6743-6751 (2011). 
23. Vogl, T. et al. Mrp8 and Mrp14 are endogenous activators of Toll-like receptor 4, promoting lethal, endotoxin-induced shock. Nature Med. 13, 1042-1049 (2007).

24. Hidalgo, A., Peired, A. J., Wild, M. K., Vestweber, D. \& Frenette, P. S. Complete identification of E-selectin ligands on neutrophils reveals distinct functions of PSGL-1, ESL-1, and CD44. Immunity 26, 477-489 (2007).

25. Hogg, N., Patzak, I. \& Willenbrock, F. The insider's guide to leukocyte integrin signalling and function. Nat. Rev. Immunol. 11, 416-426 (2011).

26. Bjork, P. et al. Identification of human S100A9 as a novel target for treatment of autoimmune disease via binding to quinoline-3-carboxamides. PLoS Biol. 7, e97 (2009).

27. Bengtsson, A. A. et al. Pharmacokinetics, tolerability, and preliminary efficacy of paquinimod (ABR-215757), a new quinoline-3-carboxamide derivative: studies in lupus-prone mice and a multicenter, randomized, double-blind, placebo-controlled, repeat-dose, dose-ranging study in patients with systemic lupus erythematosus. Arthritis Rheum. 64, 1579-1588 (2012).

28. Stadtmann, A. et al. Rapla activation by CalDAG-GEFI and p38 MAPK is involved in E-selectin-dependent slow leukocyte rolling. Eur. J. Immunol. 41, 2074-2085 (2011).

29. Yang, W. H., Nussbaum, C., Grewal, P. K., Marth, J. D. \& Sperandio, M. Coordinated roles of ST3Gal-VI and ST3Gal-IV sialyltransferases in the synthesis of selectin ligands. Blood 120, 1015-1026 (2012).

30. Zarbock, A. et al. PSGL-1 engagement by E-selectin signals through Src kinase Fgr and ITAM adapters DAP12 and FcR gamma to induce slow leukocyte rolling. J. Exp. Med. 205, 2339-2347 (2008).

31. Sarantos, M. R., Raychaudhuri, S., Lum, A. F., Staunton, D. E. \& Simon, S. I. Leukocyte function-associated antigen 1-mediated adhesion stability is dynamically regulated through affinity and valency during bond formation with intercellular adhesion molecule-1. J. Biol. Chem. 280, 28290-28298 (2005).

32. Dunne, J. L., Ballantyne, C. M., Beaudet, A. L. \& Ley, K. Control of leukocyte rolling velocity in TNF-alpha-induced inflammation by LFA-1 and Mac-1. Blood 99, 336-341 (2002).

33. Smith, M. L., Olson, T. S. \& Ley, K. CXCR2- and E-selectin-induced neutrophil arrest during inflammation in vivo. J. Exp. Med. 200, 935-939 (2004).

34. Yakubenia, S. et al. Leukocyte trafficking in a mouse model for leukocyte adhesion deficiency II/congenital disorder of glycosylation IIc. Blood 112, 1472-1481 (2008).

35. Abram, C. L. \& Lowell, C. A. The ins and outs of leukocyte integrin signaling. Annu. Rev. Immunol. 27, 339-362 (2009).

36. Xia, L. et al. P-selectin glycoprotein ligand-1-deficient mice have impaired leukocyte tethering to E-selectin under flow. J. Clin. Invest. 109, 939-950 (2002).

37. Sperandio, M., Gleissner, C. A. \& Ley, K. Glycosylation in immune cell trafficking. Immunol. Rev. 230, 97-113 (2009).

38. Deronic, A., Helmersson, S., Leanderson, T. \& Ivars, F. The quinoline-3carboxamide paquinimod (ABR-215757) reduces leukocyte recruitment during sterile inflammation: leukocyte- and context-specific effects. Int. Immunopharmacol. 18, 290-297 (2014).

39. Boyd, J. H., Kan, B., Roberts, H., Wang, Y. \& Walley, K. R. S100A8 and S100A9 mediate endotoxin-induced cardiomyocyte dysfunction via the receptor for advanced glycation end products. Circ. Res. 102, 1239-1246 (2008).

40. Turovskaya, O. et al. RAGE, carboxylated glycans and S100A8/A9 play essential roles in colitis-associated carcinogenesis. Carcinogenesis 29, 2035-2043 (2008).
41. Yago, T. et al. E-selectin engages PSGL-1 and CD44 through a common signaling pathway to induce integrin alphaLbeta2-mediated slow leukocyte rolling. Blood 116, 485-494 (2010).

42. Hoshino, K. et al. Cutting edge: Toll-like receptor 4 (TLR4)-deficient mice are hyporesponsive to lipopolysaccharide: evidence for TLR4 as the Lps gene product. J. Immunol. 162, 3749-3752 (1999).

43. Frommhold, D. et al. RAGE and ICAM-1 cooperate in mediating leukocyte recruitment during acute inflammation in vivo. Blood 116, 841-849 (2010).

44. Moser, M. et al. Kindlin-3 is required for beta2 integrin-mediated leukocyte adhesion to endothelial cells. Nature Med. 15, 300-305 (2009).

45. van den Bos, C. et al. Copurification of P6, MRP8, and MRP14 from human granulocytes and separation of individual proteins. Protein Expr. Purif. 13, 313-318 (1998).

46. Schindelin, J. et al. Fiji: an open-source platform for biological-image analysis. Nat. Methods 9, 676-682 (2012).

\section{Acknowledgements}

We thank Nadine Schmidt for technical assistance. This work was supported by Deutsche Forschungsgemeinschaft DFG - CRC914, project A1 (MM), B1 (MS) and B4 (AV), the EU-Project TARKINAID FP7-Health.2011.1.4.5 \#282095 (MS), the European Research Council (281296-ENDHOMRET to TC), by Grants from the Interdisciplinary Center of Clinical Research of the University of Muenster (Vo2/014/09 and Ro2/003/15) and CRC 1009 B8 and B9 to T.V. and J.R, from the E-RARE2 Program Treat-AID to J.R and by the Federal Ministry of Education and Research (BMBF), project AID-NET to J.R.

\section{Author contributions}

M.P. designed, performed and analysed the experiments and wrote the manuscript; A.R., M.K., K.J.C, X.C-E., S. Bieber, S. Bierschenk, I.R., K.H., M.M. and S.G. performed and analysed experiments; C.F.N., T.K.E and R.I. analysed experiments; U.K., R.P.M., D.V., A.V. and T.L. provided reagents critical for the project; T.C. and J.R. contributed to the design of the experiments and the interpretation of the data; and revised the manuscript. T.V. and M.S. designed the experiments, interpreted the data and wrote the manuscript.

\section{Additional information}

Supplementary Information accompanies this paper at http://www.nature.com/ naturecommunications

Competing financial interests: T.L. is a part-time employee of Active Biotech that develops S100A9 inhibitors for the treatment of autoimmune diseases and cancer. The remaining authors declare no competing financial interests.

Reprints and permission information is available online at http://npg.nature.com/ reprintsandpermissions/

How to cite this article: Pruenster, M. et al. Extracellular MRP8/14 is a regulator of $\beta 2$ integrin-dependent neutrophil slow rolling and adhesion. Nat. Commun. 6:6915 doi: $10.1038 /$ ncomms7915 (2015)

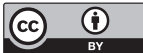

This work is licensed under a Creative Commons Attribution 4.0 International License. The images or other third party material in this article are included in the article's Creative Commons license, unless indicated otherwise in the credit line; if the material is not included under the Creative Commons license, users will need to obtain permission from the license holder to reproduce the material. To view a copy of this license, visit http://creativecommons.org/licenses/by/4.0/ 